\title{
A formação em tempos difíceis: reflexões a partir do pensamento de Edith Stein
}

\author{
Education in critical times: considerations \\ from Edith Stein's perspective
}

\section{Elton Moreira Quadros*}

Universidade do Estado da Bahia (UNEB), Paulo Afonso, BA, Brasil

\section{Resumo}

Proponho uma reflexão sobre a relação entre formação e tempos difíceis a partir da discussão indicada por Edith Stein no início da década de 1930. Nesse mesmo período, Stein também realiza outras conferências em que discute questões relacionadas com a formação. Aquela que parecia ser a perspectiva vencedora quando esse tema é abordado pela autora alemã, ou seja, a forma preconizada pelo lluminismo que estaria voltada para um destaque à quantidade de conteúdos somada à memorização. Nesse sentido, à luz do pensamento steiniano, apresentamos os impactos da crise econômica na educação na Alemanha de então, tanto do ponto de vista das questões estruturais quanto da situação dos envolvidos no processo, formadores e formados, que são atingidos por esses efeitos. Refletimos também sobre os problemas de uma concepção equivocada

* EMQ: Doutor, e-mail: eltonquadros@yahoo.com.br 
de formação que, para a autora, podem ser tão ou mais prejudiciais que os problemas derivados da crise econômica e, ao mesmo tempo, apresentamos como seria uma formação adequada segundo a perspectiva steiniana de formação, que envolve fundamentalmente a questão individual, pessoal e a relação com o mundo, tanto do ponto de vista "natural" quanto com aqueles elementos trazidos pelos formadores. Ao fim, retomamos a discussão sobre formação em tempos difíceis para pensar naquilo que pode servir de auxílio ao processo formativo e ao papel do formador em tempos sombrios. Aqui, Stein nos leva a refletir sobre os fatores culturais e, especialmente, pessoais que possam marcar o processo de formação em qualquer situação, até mesmo em tempos difíceis na economia ou na política.

Palavras-chave: Crise. Educação. Fenomenologia. Liberdade. Singularidade.

\section{Abstract}

We propose a reflection on the relation between education and critical times from the point of view presented by Edith Stein in the beginning of the 1930's. Within the same period, Stein had also given lectures in which she debated aspects related to education. Apparently, the prevailing view on education prescribed by the Enlightenment is addressed by the author, since it is oriented towards the amount of content and memorization. The impacts economic crisis had on German education is considered by those involved, both those who are responsible for education and those who are formed by this education. We think on the problems of an erroneous conception of education that can be more harmful than economic problems. At the same time, we present how an appropriate education fundamentally considers not only the individual and personal issues, but also the connection with the world according to the Steinian perspective. We also argue on education in critical times in order to think about what can help the educational process and the role the educator plays in dark times. Stein leads us to examine cultural and particularly personal elements that can highlight the educational process in any given situation such as critical times in economics or in politics.

Keywords: Crisis. Education. Phenomenology. Freedom. Singularity. 


\section{Introdução'}

Numa conferência realizada no início dos anos 30 do século passado, Edith Stein discute as implicações da crise econômica pela qual passava a Alemanha e as suas consequências para a educação e para a formação das crianças e jovens daquele período.

Neste texto, pretendo relacionar a questão da formação ao problema dos tempos difíceis. Proporei, portanto, a análise a partir da discussão, principalmente, de duas conferências realizadas por Edith Stein nos anos 30. A primeira conferência em destaque é a Tempos difíceis e formação (1932) e a segunda é Sobre o conceito de formação (1930). Outros trechos de Stein aparecem ao longo deste texto, no entanto em menor grau e sempre com uma perspectiva de reafirmar ou problematizar o que nessas duas conferências foi dito.

Iniciaremos o percurso desta conversa a partir da descrição dos tempos difíceis e a formação, passando para uma breve discussão sobre os problemas de uma concepção equivocada de formação, depois, apresentaremos as características principais para Stein desse conceito e, por fim, retornaremos aos tempos difíceis e o processo de formação, numa chave que destaque, a partir de E. Stein, o papel dos formadores em tempos sombrios.

\section{Tempos difíceis}

No início da conferência Tempos difíceis e formação, proferida em 1932 no Congresso de Formação Católica em Essen, Edith Stein nos descreve um quadro sombrio das consequências da crise econômica nas escolas naquele período: diminuição da carga horária de aulas e de alunos por classes, fechamento de escolas, proibição de aceitar novos alunos, entre outras. Stein também chama a atenção para o fechamento de algumas

1 Este texto vai dedicado aos colegas docentes, funcionários e discentes da UERJ — Universidade Estadual do Rio de Janeiro e da UENF — Universidade Estadual do Norte Fluminense que, talvez mais que quaisquer outras instituições de ensino superior brasileiras, vivem tempos difíceis. 
academias de arte (Breslau, Cassel e Konigsberg), teatros estatais e centros de ginástica regionais. Até mesmo as Faculdades populares e a Universidade sentiram os efeitos da crise econômica. Com isso, Stein faz uma ponderação sobre as incertezas da situação e suas implicações:

As consequências de tais medidas e de seus progressivos efeitos têm causado, em primeiro lugar, uma grande desordem em todas as instituições devido à incerteza da situação. A demissão ou transferência de professores tem, de diversas maneiras, tornado impossível levar adiante o trabalho com tranquilidade e constância (STEIN, 2003b, p. 388)².

Seguindo em sua descrição das consequências da crise econômica na formação, afirma que "[a] categoria dos professores é a mais prejudicada" 3 (STEIN, 2003b, p. 388), tendo em vista a redução de salário, demissões e mudanças de lugar. Tais circunstâncias ameaçam enormemente, segundo Stein, a qualidade da educação, quer no âmbito do conteúdo básico, quer no próprio acesso à instrução ${ }^{4}$.

Mas, como veremos a partir de agora, não somente os fatores econômicos podem influenciar uma crise da formação.

\section{Crise da formação}

Para Stein, a concepção equivocada sobre o conceito de formação já provocou uma situação de crise no sistema educativo, ou seja, não somente tempos difíceis do ponto de vista das questões econômicas e políticas podem causar problemas para a educação, mas é preciso entender que um olhar equivocado sobre o que seja a essência da formação, do seu conceito pode causar danos. Desconfiamos que, talvez, os danos decorrentes de um erro conceitual possam ser mais danosos para o processo educativo do

2 Las consecuencias de tales medidas y de su progresiva actuación han sido, en primer lugar, un gran desorden en todos los establecimientos debido a la incertidumbre de la situación, del despido o del traslado de los maestros; de diversas maneras ha sido totalmente imposible llevar adelante el trabajo con tranquilidad y constancia.

3 La categoria de los maestros ha sido la más danada.

4 Especialmente, a condição feminina e sua presença nas escolas, quer na condição de discentes quer como de docentes destacada pela autora. 
que os problemas econômicos. Como diz Stein (2003c, p. 196): "clamou-se e clama-se por reformas e em todas as esquinas e confins se reforma" e, se em alguns momentos podemos distinguir algumas significativas direções, no geral temos a impressão de que não conseguimos uma evolução tranquila e bem fundada, somente "experimentos preparatórios".

Stein, portanto, aponta os problemas decorrentes de uma educação baseada no ideal Iluminista e que dominou grande parte das escolas e até mesmo a universidade, que propõe um saber enciclopédico em que a alma é considerada uma tabula rasa em que se deve escrever/inscrever o máximo possível tendo como base a compreensão intelectual e a capacidade de memorização. Essa forma sofreu, desde o tempo de Stein, uma forte e generalizada crítica e, em alguns momentos, pareceu estar sobrepujada ${ }^{5}$.

Se essa concepção de formação iluminista apresentou problemas, outras foram e são tentadas, mas, se pensarmos seriamente, muitas vezes aquilo que se opôs ao modo iluminista de ser não possibilitou também grandes avanços. No imenso hipermercado de possibilidades pedagógicas e formativas, muito pouco parece, nesses nossos tempos modernos, alterar um panorama de crise interna da educação.

Stein acredita que não está necessariamente nas novidades pedagógicas a possibilidade de estabelecer um conceito de formação adequado; por isso, chama a atenção para o fato de que "desde há muito tempo vemos a luta por um novo conceito/concepção de formação que, no fundo, é um conceito de formação muito antigo" (STEIN, 2003c, p. 197) e que pretendemos descrever de modo um pouco sumário abaixo.

\section{Fenomenologia e formação}

Stein, nos seus apontamentos pessoais, sintetiza de modo forte como se dá a formação, para ela, "[t]oda formação é autoformação" (STEIN, 2003a, p. 178). Esse ponto nos parece fundamental,

5 Edith Stein não conheceu os cursos preparatórios para concurso, nem mesmo alguns cursos universitários que estão a cada dia se tornando espaços da simplificação e do utilitarismo. Em alguns casos, se uma disciplina não "serve" para concursos nem, como no meu caso de professor de filosofia do Direito, para o exame da "ordem", não presta ou não serve para nada na cabeça de alguns dos nossos alunos (e até para alguns professores). 
especialmente após apontarmos de forma breve como os tempos difíceis podem ter consequências para a educação. Mas, evidentemente, essa afirmação não é colocada em uma perspectiva em que estaríamos retomando uma noção solipsista da existência e, muito menos, da formação humana.

Precisamos ter clara uma perspectiva que está intimamente relacionada com a Fenomenologia e sua proposta metodológica.

Poderíamos definir, brevemente, a fenomenologia como a ciência que estuda o fenômeno ou aquilo que se mostra e se mostra a nós (à consciência), uma vez que nós, humanos, somos aqueles que buscamos o sentido daquilo que se mostra, o seu significado. E, nesse sentido, não estamos ligados somente ao mundo físico, uma vez que também percebemos as "coisas" intangíveis e os próprios acontecimentos, que podem envolver coisas imateriais, materiais, abstratas, sentimentos e fatos que transcendem o mundo físico.

Ora, o método fenomenológico tem como fim básico, enquanto método, buscar a significação, o sentido das coisas. Compreende que isso se dá no sujeito, uma vez que esse é o centro das vivências, e que a redução transcendental, a epoché (colocação entre parênteses do mundo e do próprio), viabiliza a descrição dos seres e, portanto, a significação a ser explicitada por meio daquela.

\section{Como se dá a formação}

Apesar de uma definição em que a formação está toda colocada na pessoa, "toda formação é autoformação", não podemos perder de vista que a formação também sempre se dá numa relação entre as capacidades internas (disposições especificas, disposição individual, essência espiritual como conhecimento e vontade) e aquilo que nos chega do exterior e que alimenta a alma, como os bens culturais, as pessoas e todo o mundo que habitamos.

Assim, podemos falar de uma formação que vem de fora e uma formação que vem de dentro (através dos impulsos, das particularidades da alma e que possui uma variedade dentro de certos limites). 
Desse modo, a psique humana tem na razão o ordenador do mundo externo na interioridade; com isso,

As potências são outros órgãos da alma, descritos por Stein como forças espirituais: a memória, a imaginação, o intelecto, a vontade, os sentidos e os sentimentos. A alma tem qualidades, também chamadas de propriedades, que são denominadas como pureza, bondade, nobreza etc.; tem estados, que são conhecidos como estados de ânimo, como a felicidade, a alegria, a tristeza, a melancolia, o medo etc.; tem disposições originais, que podem ser definidas como tendências naturais ou aptidões pessoais, que muitas vezes classificamos como vocação, dom, talento etc. (SBERGA; MASSIMI, 2015, p. 220).

Angela Ales Bello, partindo da discussão dos sentidos, apresenta como originariamente começamos a perceber o mundo interno e o mundo externo. $\mathrm{O}$ tato apresenta-se como o primeiro que "permite estabelecer os limites de nossa individualidade com relação às coisas que não somos nós", assim, "'externo' e 'interno' nascem, com efeito, de uma fusão originária que se torna uma distinção no momento em que me dou conta de ter sensação" (BELLO, 2014, p. 20). Os outros sentidos também contribuem para essa distinção que encontrará na diferenciação do outro toda uma gama de significações que nos parecem fundamentais quando pensamos o conceito de formação ${ }^{6}$.

Em grande medida, no humano, buscamos configurar a nossa psique dentro daquilo que está entre o material e o espiritual. Para Stein, esse é um ponto fundamental quando tratamos da questão da formação humana, ou seja, não podemos prescindir nenhum elemento que nos constitui, tanto aquilo que temos de material, no caso, o nosso corpo, passando pelos elementos espirituais, como vontade e conhecimento, além da dimensão do divino em nós.

Em linhas gerais, esse conceito é descrito não como "a possessão de conhecimentos exteriores, mas a configuração que a personalidade humana assume a partir da influência de múltiplas forças formadoras" (STEIN, 2003c, p. 197). Antes de todas, a configuração fundamental da

6 Aqui seria interessante pensar na questão da alteridade, mas não trataremos sobre isso neste texto. 
formação ocorre desde a interioridade. Dentro do ser humano se "esconde" uma forma interior que o leva e o impulsiona em determinada direção, algo como uma espécie de teleologia. Nessa determinada configuração, podemos encontrar, como fim, a personalidade madura, desenvolvida, uma personalidade individual singular e completamente constituída (STEIN, 2003c, p. 197).

À configuração interior somam-se outras forças que sobre ela atuam, tanto interiormente quanto exteriormente. É assim que, desde criancinhas, com nossos corpos, nossas almas e com o impulso interior e teleológico somos lançados no processo de formação. Tal como o corpo se serve de alimentos saudáveis ou prejudiciais para a sua constituição e desenvolvimento, a formação também pode ser compreendida da mesma maneira "[u]ma parte essencial de todo o processo de desenvolvimento e formação é a formação dos órgãos do corpo e da alma a partir do que esses se servem para a elaboração de sua nutrição" (STEIN, 2003c, p. 198) ${ }^{7}$.

Desse modo, as "forças" e conteúdos que nos mobilizam interna e externamente são o conjunto de elementos que nos colocam no trabalho de formação e autoformação. Entretanto, a presença dos formadores é um elemento importantíssimo como auxílio nesse processo.

\section{A contribuição do formador}

Na alma, os órgãos só alcançam sua formação na medida em que são exercitados, exercidos. Assim, os sentidos precisam ser exercitados no acomodar, diferenciar, comparar. Com isso, começamos a diferenciar cores, tons, sons etc. Já no entendimento, precisamos exercitar o pensamento e o conhecimento através, no caso da vontade, de atos volitivos (eleição, decisão, renúncia etc.), no caso da emotividade, com movimento da própria emoção, e assim por sequência.

[u]na parte esencial de todo el proceso de desarrollo y formación es la formación de los órganos de los que el cuerpo y el alma se sirven para elaborar su nutrición. 
Portanto, o planejamento de tarefas adequadas desde o exterior contribui para a formação das potencialidades que, muitas vezes, já estão no interior do ser humano de modo natural; em outros termos, "[n]ão se trata de uma interiorização de algo que vem do exterior, mas de um tirar de dentro, por meio do contato com o externo, aquilo que dentro é contido potencialmente" (BELLO, 2014, p. 25).

Para Stein, a

mão formadora que atua a partir do exterior corta as árvores silvestres emergentes [na alma] ou retira delas o alimento; está a serviço da formação desde o interior. A ação exterior programada junta-se aos influxos ambientais que atuam involuntariamente. Porém somente aquele que desde o exterior pode entrar no "interior" da alma, aquele que não se acolherá somente com sentidos e entendimento, mas que toca "o coração e o sentimento" pode crescer realmente na alma e somente isso é verdadeiramente material formativo. Porém se é realmente material formativo, se realmente se configura na alma, então deixa de ser simples material e começa a atuar configurando, educando, ajudando a alma a constituir-se naquilo que é dado a ela (STEIN, 2003c, p. 198) ${ }^{8}$.

As ações do formador, que estariam no entorno espiritual, não estão condicionadas ou limitadas à modelação primária, mas fazem parte de um conjunto maior que coloca em movimento esse caminho interior-exterior do processo formativo. Assim, as crianças são entregues aos educadores para o exercício efetivo dessa tarefa.

Na formação, mesmo que a liberdade seja um fator imprescindível, como veremos mais à frente, não podemos prescindir das atividades de outros, dos formadores humanos que fornecem materiais e, mesmo, seus corações e sentimentos, necessários a esse processo. A liberdade de ser ativo ou omisso de cada um se depara com a ação dos formadores.

8 la mano formadora que actúa desde el exterior corta tales árboles silvestres emergentes o les retira el alimento, está al servicio de la formación desde el interior. A la acción exterior programada se añaden luego los influjos ambientales que actúan involuntariamente. Pero sólo aquello que desde el exterior puede entrar en el "interior" del alma, aquello que no se acogerá solamente con sentidos y entendimiento, sino que "toca corazón y sentimiento", eso crece realmente en ella, sólo eso es realmente material formativo. Pero si es realmente material formativo, si realmente se configura en el alma, entonces deja de ser un simple material, comienza a actuar configurando, educando, ayuda al alma a la configuración determinada para el1a. 
Idealmente, esses materiais devem ser os mais adequados possíveis e oferecidos de maneira a contribuir com a assimilação real dos destinatários, mas os bons efeitos, apesar de esperados ansiosamente pelos formadores, não são por esses controlados: “[n]enhum material formativo no âmbito das obras humanas, nenhuma medida formativa de um educador pode alterar a natureza de um homem, somente pode contribuir para que continue, entre as possibilidades formativas, a escolha entre uma ou outra" (STEIN, 2003a, p. 192).

\section{Liberdade e formação}

No entanto, no processo de amadurecimento, o ser humano se depara, a partir de si, com a sua condição de ser livre. Nesse sentido, "por sua livre vontade pode ele mesmo trabalhar em sua formação, pode exercer livremente suas forças e, deste modo, pode velar por seu aperfeiçoamento, abrindo-se aos influxos educativos ou fechando-se a eles"'(STEIN, 2003c, p. 199). Com isso,nopercurso do processoeducativo/ formativo, o grau de amadurecimento poderá paulatinamente evidenciar a importância da liberdade nesse caminho, a "pessoa livre tem em suas mãos a 'si mesma', quer dizer, sua alma e seu corpo estão sob a direção da sua vontade, ainda que não incondicionalmente" (STEIN, 2003a, p. 190).

Entre os "não incondicionalmente" estão as distâncias entre o querer racional e os limites da própria constituição humana natural. Ao tentarmos passar por cima disso, os humanos, considera Stein, acabam por não conseguir uma "formação autêntica", muitas vezes ficando apenas apegados a ficções que inventam. Por isso, ao lado da noção de autoformação, Stein também destaca o autoadestramento, isto é, "o cultivo das forças através de sua colocação na ação” (STEIN, 2003a, p. 190).

No adestramento, também encontramos a dependência da liberdade, do querer instruir-se a si mesmo, não perdendo de vista os limites internos e externos para a realização satisfatória do exercício.

Na comparação que Stein realiza entre a diferença da alma animal e da alma humana, podemos compreender melhor a dimensão da 
liberdade e desse grau de possibilidade de atuação na própria formação de uma consciência, autoconsciência, que só encontramos no espírito humano:

Ele [o homem] é alguém que diz de si mesmo eu. Isso um animal não pode fazer. Quando encaro um animal nos olhos, encontro neles algo que olha a mim. Miro no seu interior, dentro de uma alma que nota o meu olhar e a minha presença. Porém trata-se de uma alma muda e prisioneira: prisioneira de si mesma, incapaz de ir atrás de si e captar-se a si mesma, incapaz de sair de si e de se aproximar de mim.

Quando encaro um homem nos olhos, seu olhar me responde/corresponde. Deixa-me embrenhar em seu interior ou me rechaça. É senhor de sua alma e pode abrir ou fechar as suas portas. Pode sair de si mesmo e entrar nas coisas. Quando dois homens se olham, estão frente a frente um eu e outro eu. Pode tratar-se de um encontro no limiar da porta ou de um encontro na interioridade. Se se trata de um encontro na interioridade, o outro eu é um tu. O olhar do homem fala. Um eu dono de si mesmo e desperto me olha a partir desses olhos. Ousemos dizer também: uma pessoa livre e espiritual. Ser pessoa quer dizer ser livre e espiritual. $\mathrm{O}$ homem é uma pessoa: é isso que o distingue de todos os outros seres da natureza' ${ }^{9}$ (STEIN, 2003d, p. 648)

No entanto não podemos perder de vista que a formação não depende somente do formando em sua liberdade. Colhemos os materiais formativos, na maioria das vezes, de fora, do mundo externo ou das relações que vivenciamos. Para Stein, o processo formativo não pode ser reduzido àquilo que comumente definimos como uma possessão exterior de conteúdos ou conhecimentos. Com isso, há a confusão de que a matéria da formação, aquilo que pode ser considerado a "matéria

9 Él es alguien que dice de símismo yo. Eso no puede hacerlo un animal. Cuando miro a un animal a los ojos, hay en ellos algo que me mira a mí. Miro dentro de un interior, dentro de un alma que nota mi mirada y mi presencia. Pero se trata de un alma muda y prisionera: prisionera en sí misma, incapaz de ir detrás de sí y de captarse a símisma, incapaz de salir de sí y acercarse a mí. Cuando miro a un hombre a los ojos, su mirada me responde. Me deja penetrar en su interior, o bien me rechaza. Es señor de su alma, y puede abrir y cerrar sus puertas. Puede salir de símismo y entrar en las cosas. Cuando dos hombres se miran, están frente a frente un yo y otro yo. Puede tratarse de un encuentro a la puerta o de un encuentro en el interior. Si se trata de un encuentro en el interior, el otro yo es un tú. La mirada del hombre habla. Un yo dueño de sí mismo y despierto me mira desde esos ojos. Solemos decir también: una persona libre y espiritual. Ser persona quiere decir ser libre y espiritual. Que el hombre es persona: esto es lo que lo distingue de todos los seres de la naturaleza. 
bruta", é confundida com a própria noção formativa. Não somente uma espécie de acúmulo indica a formação; são necessários também a disposição natural e a "atividade livre do formando". Mais que um recipiente, somos sujeitos livres em nossas singularidades.

\section{Singularidade da pessoa e formação}

Portanto, a formação não significa, segundo Stein, um conjunto de informações ou conteúdos que uma pessoa acumula ao longo de sua vida. A formação se dá em um processo que conjuga a configuração interior e os estímulos externos e, ambos, movimentam a pessoa em seu núcleo pessoal.

Aqui temos a ação dupla: de um lado, o dado interior que está intimamente relacionado com a afirmação de que toda formação é autoformação; por outro lado, os formadores externos contribuem efetivamente para que esse movimento receba estímulos e conteúdos, o que possibilita o exercício da liberdade e o amadurecimento da estrutura e da personalidade dos formandos.

Cada pessoa, apesar de estruturas semelhantes, algo como uma forma substancial, possui uma singularidade, que perpassa a sua liberdade e o seu destino. Ao ter acesso a uma formação, para além dos conteúdos, mas sem se opor a isso, compreendemos com Stein que a formação se dá em um processo contínuo que pode possibilitar o amadurecimento e o desabrochar das potencialidades pessoais.

Com isso, compreendemos a complexidade positiva que implica a dinamicidade da formação. Porém, para Stein, há uma força que está para além de todas as forças internas e externas até agora mencionadas; essa força não terá na natureza um limite, tudo que apresentamos aqui sempre terá a própria natureza das coisas e da pessoa como um limite de atuação. Assim, acredita Stein que a força da graça divina pode transformar o ser humano desde o seu interior, plasmando toda a interioridade, "[e]m resumo: a formação é algo muito mais complexo, mais misterioso, que não está submetido à arbitrariedade do que o Iluminismo se permitiu sonhar" (STEIN, 2003a, p. 190). 


\section{Formação e realidade: quando a educação se depara com tempos difíceis}

Retomando a conferência Tempos difíceis e formação, após essa breve, sintética e ainda incompleta exposição sobre o conceito de formação, percebemos que um dos primeiros problemas que se apresentaram na crise alemã das décadas de 20 e 30 na escola foi o aumento dos alunos em salas. Antes, porém, de comentar sobre esse ponto específico e seu consequente prejuízo para a qualidade da formação, o que ainda pode nos surpreender hoje é o relato steiniano sobre os benefícios da escola e sua contribuição para retirar muitas crianças e jovens de lugares, às vezes, inadequados na Alemanha de então.

No entendimento de Stein, a escola é "o lugar da educação do povo" (STEIN, 2003b, p. 391) e, por isso, foi realizado um considerável esforço, antes da crise, para corresponder a esse ideal, com a estruturação dos prédios escolares, com a escolha de métodos e matérias adequados e com a preparação do corpo docente. Tudo isso tendo em vista que a casa, os lares sozinhos "já não podem satisfazer mais em seu dever educativo" (STEIN, 2003b, p. 391). Em muitos casos, a escola acaba se convertendo, para as crianças e jovens, em um lar que não conhecem efetivamente:

Quantas pequenas criaturas que vêm da imundície e do abandono moral, fisicamente nervosos e espiritualmente em uma situação miserável começam a sentir, pela primeira vez, uma atmosfera de tranquilidade, de ordem e de paz. Pela primeira vez, bondade e pureza humanas, pela primeira vez, um hálito de amor materno, pela primeira vez, uma ideia de um mundo para além desse mundo (STEIN, 2003b, p. 391) ${ }^{10}$.

O grande número de alunos por turma dificulta o exercício da função educativa, especialmente na medida em que não é possível um tratamento pessoal que consiste em um ponto fundamental para a ação educativa segundo E. Stein.

${ }^{10}$ Cuántas pequeñas criaturas, que vienen de la inmundicia y del abandono moral, físicamente nerviosos y anímicamente en una situación miserable, comienzan a sentir aquí por primera vez una atmósfera de tranquilidad, de orden y de paz, por primera vez bondad y pureza humanas, por primera vez un hálito del amor materno, por primera vez una idea de un mundo por encima de este mundo. 
Com esse pequeno exemplo de alteração advinda como consequência da crise econômica pré-nazismo, podemos perceber que pode ser o começo para outras perdas significativas do ponto de vista educacional.

Stein apontará, em sua conferência de 1932, vários outros problemas: as ameaças aos institutos de educação especiais de então, a crise das escolas profissionais que atendem a juventude e cujos fechamento ou atuação prejudicada podem, por exemplo, gerar um aumento da criminalidade etc. Tudo isso acaba por gerar insegurança e incerteza quanto ao futuro profissional e, com isso, impede a alegria do trabalho, o ânimo em escolher um caminho que leve em consideração as capacidade naturais de cada um, o que pode ameaçar "toda a nossa livre produção cultural"11 (STEIN, 2003b, p. 393). Esse outro ponto demonstra, para mim, mais uma vez, como o pensamento de E. Stein não está desencarnado das realidades temporais e humanas mais cotidianas.

Muitas outras consequências a crise econômica provoca nas escolas e universidades, não perdendo de vista as questões trabalhistas de professores e funcionários, bem como a pauperização das condições mínimas de trabalho. Entretanto talvez uma das mais difíceis consequências dos tempos de crise é cairmos em um pessimismo inativo, na paralisação lamentosa que não contribui para a efetivação da força vital do humano.

Mesmo que a formação dependa de subsídios materiais, em sua essência, é uma obra do espírito e, por isso, possui fontes inesgotáveis:

Os homens necessitados, sejam adultos ou crianças, pedem algo mais que bens culturais objetivos, pedem bens e calor humanos. E para fazer acessíveis os bens objetivos, para dispender uma força formativa de sua humanidade, é necessário vivê-los em si mesmo e deixar que surjam de si mesmos em modo vivo o que se tem no interior ${ }^{12}$ (STEIN, 2003b, p. 394).

11 toda nuestra libre producción cultural.

12 Los hombres necesitados, sean adultos o niños, piden algo más que bienes culturales objetivos, piden bienes y calor humanos. Y para hacer accesibles los bienes objetivos, para dispensarles una fuerza formativa de su humanidad, es necesario vivirlos en sí mismo y dejar que surjan de sí mismos en modo vivo lo que se tiene en el interior. 
Portanto, não podemos prescindir da noção de que toda formação é autoformação e, por princípio, podemos perceber a profunda necessidade de que isso incida na vida dos próprios formadores. $\mathrm{O}$ trabalho interior em relação com as fontes externas precisa ser vivido por nós, educadores, sem perder de vista que "todas as questões que hoje determinam e angustiam os homens, a pesada situação de necessidade, exigem discussão e solução"13 (STEIN, 2003b, p. 394). Não há como ficar alheio às "crianças na escola, aos companheiros de trabalho, aos compatriotas que vivem em necessidade, essas situações clamam ao nosso coração e, certamente, não necessitam somente do que temos, mas especialmente necessitam daquilo que somos"14 (STEIN, 2003b, p. 394). Para E. Stein, "não poderemos voltar atrás se queremos ajudar

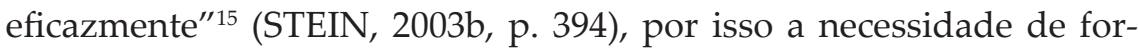
madores maduros, autênticos, que realizem também em si o empenho do amadurecimento e, assim, possam realizar um trabalho criativo a serviço da comunidade.

Essa é uma grande tarefa que os educadores/formadores têm à frente, ajudar naquilo que é indispensável do ponto de vista material, mas também "traçar novos caminhos e animar os homens que tenham perdido o ânimo e tenham deixado a amargura prevalecer, para que juntem coragem e confiança e sejam capazes de ir por novos caminhos"16 (STEIN, 2003b, p. 395). Como se dirige a um público católico, E. Stein termina a sua análise sobre a formação em tempos difíceis marcando os bens advindos da Igreja Católica para o enfrentamento desses tempos. Aqui, não nos determos mais pormenorizadamente nisso, só trazemos um trecho que nos parece sintético dos anseios da autora:

Certamente, se cremos encontrar a força somente em nós mesmo, nossa riqueza interior pode esgotar-se rapidamente. Pode-se encontrar a si

${ }^{13}$ todas las cuestiones que hoy determinan y angustian a los hombres, y la pesada situación de necesidad, exigen discusión y solución.

${ }^{14}$ Los niños en la escuela, los compañeros de trabajo, los compatriotas que viven en necesidad, Ilaman a nuestro corazón; no necesitan sólo lo que tenemos, sino aquello que somos.

15 Y no podemos volvemos atrás si queremos ayudar eficazmente.

${ }^{16}$ trazar nuevos caminos y animar a los hombres que han perdido el ánimo y han dejado que la amargura se les impusiese, de tal modo que junten valentía y confianza y sean capaces de ir por estos nuevos caminos. 
mesmo pobre e não ter nada a dar. Para não ter que estar sempre com as mãos vazias frente aos necessitados de ajuda, temos que acudir às fontes eternas, as fontes da vida da graça. Conduzir até elas é o maior trabalho formativo, a mais eficaz das ajudas (STEIN, 2003b, p. 390) ${ }^{17}$.

Para E. Stein, tanto a formação em si quanto o enfrentamento dos tempos difíceis encontrarão seu sentido e modo de ser efetivos nas fontes da vida da graça.

\section{Considerações finais}

Realizar uma reflexão sobre o estado da educação em tempos difíceis, em tempos de crise, acompanhando os passos de Edith Stein, em si mesmo, já nos faz pensar sobre o estado de crise na educação que estamos vivendo em nosso país (e quiçá no mundo).

Não tenho a intenção de adentrar, nesse momento, em uma análise que discuta a questão da crise e sua influência na educação no Brasil, mas uma esperança, talvez a única que reste em tempos sombrios, seja a que traz a própria Stein. Ela diz que não precisamos desesperar-nos, uma vez que existe uma gama considerável de bens espirituais e culturais, e fará uma lista considerável e surpreendente destes bens, tais como as montanhas, bosques, rios e lagos alemães, a glória romântica, com seus castelos e catedrais, as cidades antigas, com suas "ruas tortuosas"; lembrará, ainda, do patrimônio musical (cantos), das fábulas, entre outros elementos da cultura popular. Tudo isso temos, referindo-se a um público de professores, diante de nós, sempre de maneira acessível se estamos abertos.

Se estamos abertos a isso, teremos como levar adiante obras formativas que estão relacionadas a "abrir o espírito e o coração dos alunos para receber essa riqueza" (STEIN, 2003b, p. 390) que podemos encontrar tanto na história de um povo, como na própria memória do humano.

17 Ciertamente, si creemos encontrar la fuerza en nosotros mismos solamente, nuestra riqueza interior puede agotarse rápidamente. Se puede encontrar uno a sí mismo pobre y no tener nada más que dar. Para no tener que estar nunca con las manos vacías frente a necesitados de ayuda, hay que acudir a las fuentes eternas, a las fuentes de la vida de la gracia. Conducir hasta ellas es el máximo trabajo formativo, la más eficaz de las ayudas". 
E aqui repito um trecho que parece fundamental sobre os nossos tempos e a todos os que nos circundam no processo formativo: as pessoas, assim diz E. Stein, "necessitam não somente do que temos, mas daquilo que somos"18 (STEIN, 2003b, p. 390).

Ora, em tempos difíceis, quando as crises econômicas ou civilizacionais atacam, os educadores sempre terão o patrimônio material ou imaterial da cultura humana, mas, fundamentalmente, terão aquilo que são para oferecer aos alunos, aos seus formandos e a cada um que encontrarem pelo caminho.

\section{Referências}

BELLO, A. A. "INTRAPESSOAL" e "INTERPESSOAL": linhas gerais de uma antropologia filosófico-fenomenológica. In: SAVIAN FILHO, J. (org.). Empatia - Edmund Husserl e Edith Stein - Apresentações didáticas. São Paulo: Edições Loyola, 2014.

SBERGA, A. A.; MASSIMI, M. A formação da pessoa em Edith Stein, princípios educativos e aproximação com o Sistema Preventivo de Dom Bosco. Ciências da Educação, UNISAL, Americana, ano XVII, n. 32, p. 209-228, jan./jun. 2015.

STEIN, E. Sobre el concepto de formación. In: STEIN, E. Obras completas. Vol. IV. Escritos antropológicos y pedagógicos. Vitória; Madrid; Burgos: Ediciones El Carmen; Editorial Espiritualidad; Editorial Monte Carmelo, 2003a.

STEIN, E. Tiempos difíciles y formación. In: STEIN, E. Obras completas. Vol. IV. Escritos antropológicos y pedagógicos. Vitória; Madrid; Burgos: Ediciones El Carmen; Editorial Espiritualidad; Editorial Monte Carmelo, 2003b.

STEIN, E. Fundamentos de la formación de la mujer. In: STEIN, E. Obras completas. Vol. IV. Escritos antropológicos y pedagógicos. Vitória; Madrid; Burgos: Ediciones El Carmen; Editorial Espiritualidad; Editorial Monte Carmelo, 2003c.

${ }^{18}$ necesitan no sólo lo que tenemos, sino lo que somos. 
STEIN, E. Estructura de la persona humana. In: STEIN, E. Obras completas. Vol. IV. Escritos antropológicos y pedagógicos. Vitória; Madrid; Burgos: Ediciones El Carmen; Editorial Espiritualidad; Editorial Monte Carmelo, 2003d.

\section{Obras consultadas}

STEIN, E. Grundlagen der Frauenbildung. In: STEIN, E. Die Frau Fragestellungen und Reflexionen. ESGA 13. Freiburg; Basel; Wien: Herder, 2010a.

STEIN, E. Der Aufbau der menschlichen Person. Vorlesung zur philosophischen Antropologie. ESGA 14. Freiburg; Basel; Wien: Herder, $2010 \mathrm{~b}$.

STEIN, E. Notzeit und Bildung. In: STEIN, E. Bildung und entfaltung der individualitat: beitrage zum christlichen erziehungsauftrag. ESGA 16. Freiburg; Basel; Wien: Herder, 2004a.

STEIN, E. Zur Idee der Bildung. In: STEIN, E. Bildung und entfaltung der individualitat: beitrage zum christlichen erziehungsauftrag. ESGA 16. Freiburg; Basel; Wien: Herder, 2004b.

Recebido: 22/09/2017

Received: 09/22/2017

Aprovado: 30/10/2017

Approved: 10/30/2017 